\title{
Prevalence and dissemination of the Ser315Thr substitution within the KatG enzyme in isoniazid- resistant strains of Mycobacterium tuberculosis isolated in Uruguay
}

Correspondence

Gustavo Varela

gvarela@higiene.edu.uy

Received 12 March 2008

Accepted 20 August 2008

\author{
Gustavo Varela, ${ }^{1}$ Sabina González, ${ }^{1}$ Pilar Gadea, ${ }^{1}$ Cecilia Coitinho, ${ }^{2}$ \\ Inés Mota, ${ }^{1}$ Gladys González, ${ }^{1}$ Fernando Goñi, ${ }^{3,4}$ Carlos Rivas $^{2}$ \\ and Felipe Schelotto ${ }^{1}$ \\ ${ }^{1}$ Department of Bacteriology and Virology, Institute of Hygiene, Universidad de la República, Av. \\ Alfredo Navarro 3051, Montevideo, Uruguay \\ ${ }^{2}$ Laboratory Department, Honorary Anti-Tuberculosis Commission, 18 de Julio 2175, Montevideo, \\ Uruguay \\ ${ }^{3}$ Department of Immunology, School of Chemistry, Universidad de la República, Av. Alfredo Navarro \\ 3051, Montevideo, Uruguay \\ ${ }^{4}$ Department of Neurology, New York University School of Medicine, New York, USA
}

\section{INTRODUCTION}

The use of isoniazid (INH), rifampicin (RIF) and pyrazinamide constitutes the backbone of the directly observed therapy short-course, or DOTS, treatment for tuberculosis (TB). INH, a first-line antituberculosis drug, is very efficient at killing bacilli in the active metabolic state; however, the increase in INH-resistant strains has reduced the efficacy of this drug as a disease control agent in certain populations (WHO, 2000, 2004).

INH is a pro-drug activated by the bifunctional bacterial catalase-peroxidase enzyme encoded by the kat $G$ gene (Bardou et al., 1998; Wallace \& Griffith, 2005). It produces free radicals that in turn are toxic to different bacterial molecules (Sacchettini \& Blanchard, 1996).

The mechanisms associated with INH resistance in Mycobacterium tuberculosis include mutations in several genes. These changes have been identified mainly in the $k a t G$, inhA, kasA and $n d h$ genes. In addition, mutations in

Abbreviations: DRE, double repetitive element; INH, isoniazid; RIF, rifampicin; TB, tuberculosis. the furA, iniA, iniB and $i n i C$ genes have been found in INH-resistant strains (Piatek et al., 2000; Ramaswamy \& Musser, 1998; Ramaswamy et al., 2003).

The prevalence of mutations in $k a t G$ varies among different regions of the world, with rates ranging from $7 \%$ in Finland to $94 \%$ in North-West Russia (Marttila et al., 1996; Mokrousov et al., 2002). Approximately 70-90\% of the mutations in the kat $G$ gene are located in codon 315 , with the most frequent substitution being serine to threonine (AGC $\rightarrow$ ACC) (Hazbón et al., 2006; HerreraLeón et al., 2005; Leung et al., 2003; Silva et al., 2003).

The aim of this work was to determine the prevalence of the Ser315Thr substitution in INH-resistant strains of M. tuberculosis in Uruguay, and to determine whether it was associated with other epidemiological and phenotypic characteristics that could influence dissemination.

\section{METHODS}

M. tuberculosis isolates. In Uruguay, the Mycobacteriology Laboratory of the Honorary Anti-Tuberculosis Commission is the 
national reference centre for mycobacteria, and receives at least $95 \%$ of the specimens detected in the country as a whole. In this study, we analysed all $M$. tuberculosis cultures resistant to INH (62 strains) isolated between 1999 and 2005 at this laboratory from the respiratory tracts of 69 patients. We also studied 14 INH-susceptible strains. Ten of these isolates corresponded to five patients who presented with a susceptible strain before treatment and an INH-resistant strain during the course of standard treatment with RIF, INH and pyrazinamide. These cases were defined as treatment failure. Another four isolates were recovered from two patients defined as having a relapse of TB. Clinically and epidemiologically relevant information from each patient including human immunodeficiency virus status and demographic data were obtained from the National Tuberculosis Register of Uruguay.

Catalase activity assay. A semi-quantitative catalase test was carried out on all strains according to a standard procedure (Vincent et al., 2003). M. tuberculosis H37Rv was included as a positive control.

Drug-susceptibility testing. INH resistance was determined using the proportion method in Löwenstein-Jensen medium containing 0.2

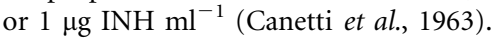

Bacterial DNA isolation. For DNA extraction, a loopful of each bacterial growth on Löwenstein-Jensen medium was suspended in $1 \mathrm{ml}$ distilled water, boiled for $10 \mathrm{~min}$ in a water bath, frozen at $-80{ }^{\circ} \mathrm{C}$ overnight, thawed and centrifuged at 12000 r.p.m. in a microfuge for $10 \mathrm{~min}$. The supernatants were used as DNA templates for amplification reactions.

RFLP-PCR for katG. The reaction protocol was carried out as described by Leung et al. (2003). The primers used were katG-F 904 (5'-AGCTCGTATGGCACCGGAAC-3') and katG-R 1523 (5'-TTGACCTCCCACCCGACTTG-3' ${ }^{\prime}$. Amplification was performed in $25 \mu \mathrm{l}$ PCR mixture containing $0.2 \mu \mathrm{M}$ each primer, $2 \mathrm{mM} \mathrm{MgCl}_{2}, 1.5 \mathrm{U}$ Taq DNA polymerase (Invitrogen) and $200 \mu \mathrm{M}$ dNTPs. The amplification steps were as follows: initial denaturation for $4 \mathrm{~min}$ at $95{ }^{\circ} \mathrm{C}$; 45 cycles of $1 \mathrm{~min}$ at $94{ }^{\circ} \mathrm{C}, 60{ }^{\circ} \mathrm{C}$ for $1 \mathrm{~min}$ and $72{ }^{\circ} \mathrm{C}$ for $1 \mathrm{~min}$; and a final extension for $10 \mathrm{~min}$ at $72{ }^{\circ} \mathrm{C}$. The $620 \mathrm{bp}$ fragment of the kat $G$ gene was digested at $37{ }^{\circ} \mathrm{C}$ for $4 \mathrm{~h}$ with $\mathrm{Msp} \mathrm{I}$ restriction endonuclease (New England Biolabs), followed by electrophoresis in a $6 \%$ polyacrylamide gel. The pattern of bands was visualized under UV light using ethidium bromide. This procedure was applied to all strains.

Double-repetitive-element (DRE) PCR. This assay was performed as described by Friedman et al. (1995) and Varela et al. (2005) on all RFLP-PCR pattern $C$ strains, on the ten isolates recovered from patients with treatment failure and on the four strains isolated from two patients with a relapse of TB. The primers used were Ris1 (5'-GGCTGAGGTCTCAGATCAG- $\left.3^{\prime}\right)$ and Ris2 ( $5^{\prime}$-ACCCCATCCTTTCCAAGAAC- $\left.3^{\prime}\right)$, and Pntb1 (5'-CCGTTGCCGTACAGCTG-3') and Pntb2 (5'-CCTAGCCGAACCCTTTG-3'). The amplification products were examined by $2 \%(w / v)$ agarose gel electrophoresis. A GeneAmp PCR system 2700 thermal cycler (Applied Biosystems) was used for all amplification reactions.

\section{RESULTS AND DISCUSSION}

This is believed to be the first study in Uruguay of the association of INH resistance with the AGC $\rightarrow$ ACC substitution at codon 315 of the $k a t G$ gene. A total of 16 of the $62(26 \%)$ INH-resistant $M$. tuberculosis strains showed pattern C by RFLP-PCR (Fig. 1, lane 3), which corresponds to the Ser315Thr substitution. Similar results have been obtained in Singapore where the prevalence of

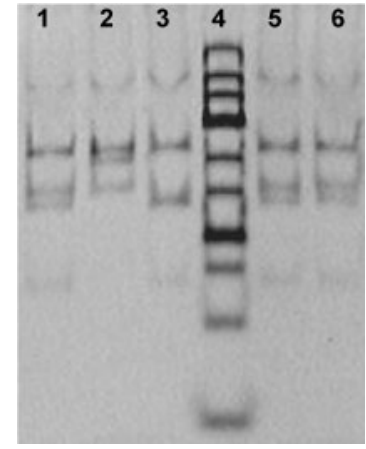

Fig. 1. RFLP-PCR patterns of katG amplicons after Mspl digestion. Lane: 1,5 and 6 , strains $\mathrm{H} 9, \mathrm{H} 17$ and $\mathrm{H} 65$, respectively, with pattern $A ; 2$, strain $\mathrm{IH} 8$ with pattern $B$; 3 , strain IH43 with pattern C; 4, 25 bp DNA ladder (low range GeneRuler; Fermentas).

TB is intermediate and the Ser315Thr substitution represents $26 \%$ of the INH-resistant isolates (Lee et al., 1999). In contrast, in North-West Russia where the prevalence of TB is 278.2 per 100000 of the population, Mokrousov et al. (2002) found a prevalence of the Ser315Thr substitution close to $95 \%$, which strongly suggests a dissemination of particular strains.

We analysed at least $95 \%$ of the INH-resistant strains present in Uruguay during the period 1999-2005 and could not establish any epidemiological link between 15 of the 16 patients infected with pattern $\mathrm{C}$ strains. In addition, 15 of the 16 strains with RFLP-PCR pattern $C$ had different profiles by DRE-PCR, suggesting that there is no predominant pattern $\mathrm{C} / \mathrm{INH}$-resistant strain linked to dissemination (Fig. 2a).

It has been postulated that Ser315Thr substitution confers intermediate- to high-level resistance to INH by binding of KatG to INH without suppressing the catalase activity (Abate et al., 2001; Cardoso et al., 2004; Gagneux et al., 2006; Zhang et al., 2005). We found that 13 of the 16 strains ( $81 \%)$ with pattern $\mathrm{C}$ grew in the presence of $1 \mu \mathrm{g} \mathrm{INH} \mathrm{ml}{ }^{-1}$.

van Soolingen et al. (2000) postulated that strains that already have the Ser315Thr substitution have more possibility of acquiring mutations in other genes. In this respect, we found that 8 of the 16 strains (50\%) with the Ser315Thr substitution showed resistance to other drugs such as RIF and streptomycin, whereas only 5 out of 33 INH-resistant strains (15\%) with pattern A by RFLP-PCR (which corresponds to serine in position 315 and arginine in position 463) (Fig. 1, lanes 1, 5 and 6) showed other phenotypes associated with resistance.

A total of 12 of the 16 strains with Ser315Thr substitution were recovered from patients defined as new TB cases according to World Health Organization recommendations (WHO, 2002). Two of these strains showed the same band profile by DRE-PCR assay (Fig. 2b) and were isolated from 
(a)

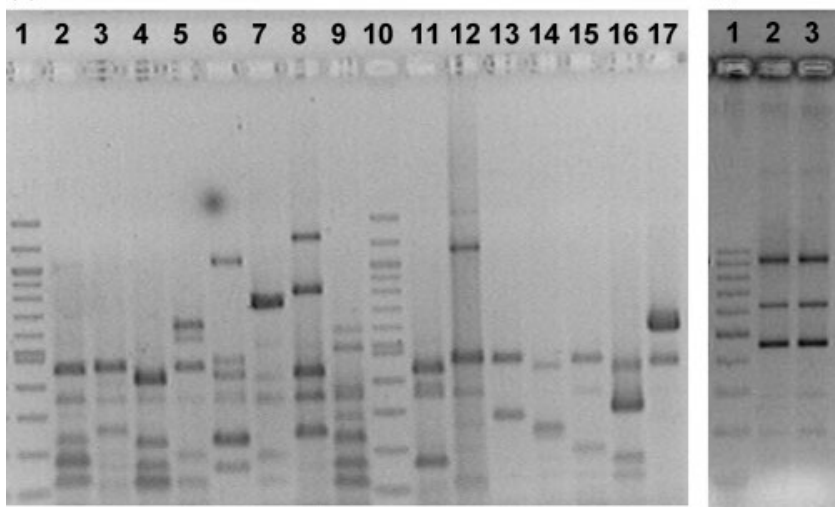

Fig. 2. (a) DRE-PCR of INH-resistant strains of M. tuberculosis with pattern $C$ recovered from patients without epidemiological links. Lane: 1 and 10, 100 bp DNA ladder (New England BioLabs); 2, M. tuberculosis H37Rv; 3, strain $\mathrm{IH} 11$; 4, strain $\mathrm{IH} 18$; 5, strain $\mathrm{IH} 24 ; 6$, strain $\mathrm{IH} 27 ; 7$, strain $\mathrm{IH} 31 ; 8$, strain $\mathrm{IH} 36$; 9, strain $\mathrm{IH} 41 ; 11$, strain $\mathrm{IH} 43 ; 12$, strain $\mathrm{IH} 45 ; 13$, strain $\mathrm{IH} 52 ; 14$, strain IH59; 15, strain IH63; 16, strain IH72; 17, strain IH74. (b) DRE-PCR from INH-resistant strains of $M$. tuberculosis with pattern $C$ recovered from two brothers living together. Lane: 1, 100 bp DNA ladder (GeneRuler; Fermentas); 2, strain IH33 and 3, strain $\mathrm{IH} 38$.

two brothers who lived together, which suggests a common origin of infection or transmission between them. These results are in agreement with previous reports that showed that INH-resistant strains of M. tuberculosis with a Ser315Thr substitution are capable of producing secondary cases of TB (Gagneux et al., 2006). The remaining four strains with a Ser315Thr substitution were obtained from patients who had previously received antituberculosis treatment.

As reported in other regions (Bakonyte et al., 2003; Haas et al., 1997; Marttila et al., 1996), the presence in Uruguay of a $k a t G$ gene deletion was low, being found in only $2(3 \%)$ of the $62 \mathrm{INH}$-resistant strains. These strains grew in the presence of INH at a concentration of $1 \mu \mathrm{g} \mathrm{ml}^{-1}$ and showed no catalase activity.

A single INH-resistant strain with pattern B corresponding to Ser315 and Leu463 was recovered from one immigrant of Chinese origin, who arrived in Uruguay 2 years previously (Fig. 1, lane 2). The low occurrence of this mutation agrees with a previous study conducted in the neighbouring country of Brazil (Cardoso et al., 2004).

All strains recovered from five individual cases defined as treatment failure showed pattern A by RFLP-PCR. These results suggest that the Ser315Thr substitution is not frequently associated with this situation. Four out of five of these cultures showed sequences related to kat $G$ by PCR and had no catalase activity (Table 1). The strains from different individuals with treatment failure showed different band patterns by DRE-PCR assay, but in each individual patient the same band distribution was seen for the INH-susceptible and INH-resistant strains recovered before and after treatment (Fig. 3).

Two pairs of strains corresponding to relapses of TB after 1 and 2 years, respectively, showed pattern $\mathrm{A}$ in the INHresistant isolates and displayed an identical band distribution by DRE-PCR assay (Fig. 1). A total of 15 (45\%) of the 33 remaining INH-resistant strains with pattern A were isolated from patients who had not received antituberculosis treatment and all INH-susceptible isolates analysed showed pattern A in RFLP-PCR (Fig. 1). Three strains showed particular and unique profiles not described before and apparently not involving Ser315Thr or Arg463Leu.

In summary, we found the following results. (i) In Uruguay the prevalence of the Ser315Thr substitution in KatG in INH-resistant $M$. tuberculosis strains was intermediate $(26 \%)$ and similar to figures reported in regions with a comparable prevalence of TB. The intermediate prevalence of Ser315Thr substitution precludes the use of RFLP-PCR as a rapid tool for the screening of INH resistance. (ii) Using DRE-PCR, we found no clonal dissemination of any

Table 1. INH-susceptible and INH-resistant M. tuberculosis strains isolated from patients with treatment failure in Uruguay

\begin{tabular}{|c|c|c|c|c|c|c|c|}
\hline \multirow[t]{2}{*}{ Patient no. } & \multirow[t]{2}{*}{$\begin{array}{c}\text { HIV } \\
\text { status }^{*}\end{array}$} & \multirow{2}{*}{$\begin{array}{c}\text { Time between } \\
\text { isolation of the } \\
\text { two strains (days) }\end{array}$} & \multirow{2}{*}{$\begin{array}{l}\text { Other drugs to } \\
\text { which the second } \\
\text { isolate was resistant }\end{array}$} & \multicolumn{2}{|c|}{$\begin{array}{l}\text { Height }(\mathrm{mm}) \text { in } \\
\text { catalase test }\end{array}$} & \multirow[t]{2}{*}{$\begin{array}{l}\text { DRE-PCR pattern } \\
\text { (both strains) }\end{array}$} & \multirow{2}{*}{$\begin{array}{c}\text { S315T/R463L } \\
\text { substitutions } \\
\text { (both strains) } \dagger\end{array}$} \\
\hline & & & & $\begin{array}{l}\text { INH-S } \\
\text { strains }\end{array}$ & $\begin{array}{l}\text { INH-R } \\
\text { strains }\end{array}$ & & \\
\hline CLA 14 & Negative & 62 & - & 15 & 0 & $\mathrm{~A} / \mathrm{A}$ & $-1-$ \\
\hline CLA 23 & Negative & 60 & RIF & 18 & 0 & $\mathrm{~B} / \mathrm{B}$ & $-1-$ \\
\hline CLA 32 & Negative & 68 & - & 23 & 0 & $\mathrm{C} / \mathrm{C}$ & $-1-$ \\
\hline CLA 48 & Negative & 63 & - & 8 & 0 & $\mathrm{D} / \mathrm{D}$ & $-1-$ \\
\hline CLA 57 & Negative & 66 & - & 18 & 16 & $\mathrm{E} / \mathrm{E}$ & $-1-$ \\
\hline
\end{tabular}

HIV, Human immunodeficiency virus; INH-R, INH resistant; INH-S, INH susceptible.

${ }^{*}$ Determined by enzyme immunoassay (AxSYM; Abbott Laboratories).

$\dagger-$, absence of substitutions as determined by RFLP-PCR. 


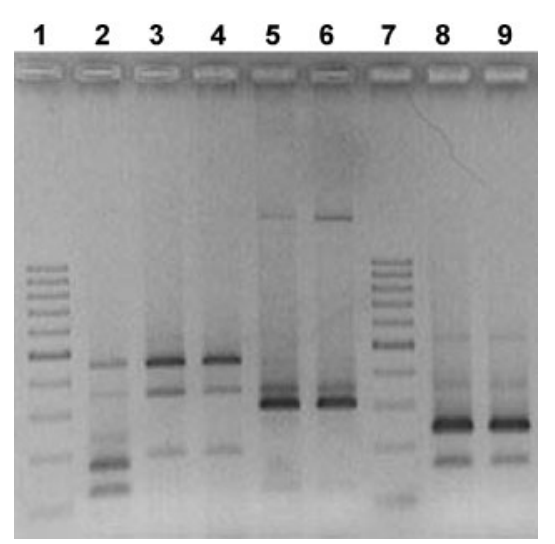

Fig. 3. DRE-PCR of strains of $M$. tuberculosis recovered from three of five patients with treatment failure. Lane: 1 and 7, $100 \mathrm{bp}$ DNA ladder (GeneRuler; Fermentas); 2, M. tuberculosis H37Rv; 3 and 4 , strains $A$ and $B$ isolated from patient CLA $14 ; 5$ and 6 , strains $A$ and $B$ isolated from patient CLA 23; 8 and 9 , strains $A$ and $B$ isolated from patient CLA 32. Strains identified as $A$ corresponded to $\mathrm{INH}$-susceptible isolates recovered before treatment and strains identified as $\mathrm{B}$ to $\mathrm{INH}$-resistant isolates recovered 2 months after starting the antituberculosis treatment.

particular INH-resistant strain of $M$. tuberculosis carrying the Ser315Thr substitution. (iii) Deletions in the kat $G$ gene in INH-resistant strains of $M$. tuberculosis are rare. (iv) More-refined techniques are needed to map the whole array of mutations/deletions leading or related to $\mathrm{INH}$ resistance and multidrug resistance. A comprehensive classification of $M$. tuberculosis strains will be critical in determining future antituberculosis therapies in a dynamic and efficient TB control programme.

\section{ACKNOWLEDGEMENTS}

We thank Juan A. Ayala for critical reading of the manuscript and English language corrections.

\section{REFERENCES}

Abate, G., Hoffner, S. E., Thomsen, V. O. \& Miorner, H. (2001). Characterization of isoniazid-resistant strains of Mycobacterium tuberculosis on the basis of phenotypic properties and mutations in katG. Eur J Clin Microbiol Infect Dis 20, 329-333.

Bakonyte, D., Baranauskaite, A., Cicenaite, J., Sosnovskaja, A. \& Stakenas, P. (2003). Molecular characterization of isoniazid-resistant Mycobacterium tuberculosis clinical isolates in Lithuania. Antimicrob Agents Chemother 47, 2009-2011.

Bardou, F., Raynaud, C., Ramos, C., Laneele, M. A. \& Laneele, G. (1998). Mechanism of isoniazid uptake in Mycobacterium tuberculosis. Microbiology 144, 2539-2544.

Canetti, G., Rist, N. \& Grosset, J. (1963). Measurement of sensitivity of the tuberculous bacillus to antibacillary drugs by the method of proportions. Methodology, resistance criteria, results and interpretation. Rev Tuberc Pneumol 27, 217-272 (in French).
Cardoso, R. F., Cooksey, R. C., Morlock, G. P., Barco, P., Cecon, L., Forestiero, F., Leite, C. Q. F., Sato, D. N., Shikama, M. L. \& other authors (2004). Screening and characterization of mutations in isoniazid-resistant Mycobacterium tuberculosis isolates obtained in Brazil. Antimicrob Agents Chemother 48, 3373-3381.

Friedman, C. R., Stoeckle, M. Y., Johnson, W. D. \& Riley, L. W. (1995). Double-repetitive-element PCR method for subtyping Mycobacterium tuberculosis clinical isolates. J Clin Microbiol 33, 1383-1384.

Gagneux, S., Burgos, M. V., DeRiemer, K., Enciso, A., Muñoz, S., Hopewell, P. C., Small, P. M. \& Pym, A. S. (2006). Impact of bacterial genetics on the transmission of isoniazid-resistant Mycobacterium tuberculosis. PLoS Pathog 2, 603-610.Medline

Haas, W. H., Schilke, K., Brand, J., Amthor, B., Weyer, K., Fourie, R. B., Bretzel, G., Sticht-Groh, V. \& Bremer, H. J. (1997). Molecular analysis of $k a t G$ gene mutations in strains of Mycobacterium tuberculosis complex from Africa. Antimicrob Agents Chemother 41, 1601-1603.

Hazbón, M. H., Brimacombe, M., Bobadilla del Valle, M., Cavatore, M., Inírida Guerrero, M., Varma-Basil, M., Billman-Jacobe, H., Lavender, C., Fyfe, J. \& other authors (2006). Population genetics study of isoniazid resistance mutations and evolution of multidrugresistant Mycobacterium tuberculosis. Antimicrob Agents Chemother 50, 2640-2649.

Herrera-León, L., Molina, T., Saíz, P., Sáez-Nieto, J. A. \& Soledad Jiménez, M. (2005). New multiplex PCR for rapid detection of isoniazid-resistant Mycobacterium tuberculosis clinical isolates. Antimicrob Agents Chemother 49, 144-147.

Lee, A. S. G., Lim, I. H. K., Tang, L. L. H., Telenti, A. \& Wong, S. Y. (1999). Contribution of kasA analysis to detection of isoniazidresistant Mycobacterium tuberculosis in Singapore. Antimicrob Agents Chemother 43, 2087-2089.

Leung, E. T., Kam, K. M., Chiu, A., Ho, P. L., Seto, W. H., Yuen, K. Y. \& Yam, W. C. (2003). Detection of katG Ser315Thr substitution in respiratory specimens from patients with isoniazid-resistant Mycobacterium tuberculosis using PCR-RFLP. J Med Microbiol 52, 999-1003.

Marttila, H. J., Soini, H., Huovinen, P. \& Viljanen, M. K. (1996). katG mutations in isoniazid-resistant Mycobacterium tuberculosis isolates recovered from Finnish patients. Antimicrob Agents Chemother 40, 2187-2189.

Mokrousov, I., Narvskaya, O., Otten, T., Limeschenko, E., Steklova, L. \& Vyshnevskiy, B. (2002). High prevalence of KatG Ser315Thr substitution among isoniazid-resistant Mycobacterium tuberculosis clinical isolates from northwestern Russia, 1996 to 2001. Antimicrob Agents Chemother 46, 1417-1424.

Piatek, A. S., Telenti, A., Murray, M. R., El-Hajj, H., Jacobs, W. R., Jr, Kramer, F. R. \& Alland, D. (2000). Genotypic analysis of Mycobacterium tuberculosis in two distinct populations using molecular beacons: implication for rapid susceptibility testing. Antimicrob Agents Chemother 44, 103-110.

Ramaswamy, S. \& Musser, J. M. (1998). Molecular genetic basis of antimicrobial agent resistance in Mycobacterium tuberculosis: update. Tuber Lung Dis 79, 3-29.

Ramaswamy, S. V., Reich, R., Dou, S.-J., Jasperse, L., Pan, X., Wanger, A., Quitugua, T. \& Graviss, E. A. (2003). Single nucleotide polymorphisms in genes associated with isoniazid resistance in Mycobacterium tuberculosis. Antimicrob Agents Chemother 47, 1241-1250.

Sacchettini, J. C. \& Blanchard, J. S. (1996). The structure and function of the isoniazid target in Mycobacterium tuberculosis. Res Microbiol 147, 36-43.

Silva, M. S., Senna, S. G., Ribeiro, M. O., Valim, A. R., Telles, M. A., Kritski, A., Morlock, G. P., Cooksey, R. C., Zaha, A. \& Rossetti, M. L. (2003). Mutations in $k a t G$, inhA, and $a h p C$ genes of Brazilian 
isoniazid-resistant isolates of Mycobacterium tuberculosis. J Clin Microbiol 41, 4471-4474.

van Soolingen, D., de Haas, P. E. W., van Doorn, H. R., Kuijper, E., Rinder, H. \& Borgdorff, M. W. (2000). Mutations at amino acid position 315 of the $k a t G$ gene are associated with high-level resistance to isoniazid, other drug resistance, and successful transmission of Mycobacterium tuberculosis in The Netherlands. J Infect Dis 182, 1788-1790.

Varela, G., Carvajales, S., Gadea, P., Sirok, A., Grotiuz, G., Mota, M. I., Ritacco, V., Reniero, A., Rivas, C. \& Schelotto, F. (2005). Comparative molecular study of Mycobacterium tuberculosis strains, in times of antimicrobial drug resistance. Rev Argent Microbiol 37, 11-15.

Vincent, V., Brown Elliott, B. A., Jost, K. C., Jr \& Wallace, R. C., Jr (2003). Mycobacterium: phenotypic and genotypic identification. In Manual of Clinical Microbiology, 8th edn, pp. 560-584. Edited by P. R. Murray, E. J. Baron, M. A. Pfaller, J. H. Jorgensen \& R. H. Yolken. Washington, DC: American Society for Microbiology.
Wallace, R. J. \& Griffith, D. E. (2005). Antimycobacterial agents. In Principles and Practice of Infectious Diseases, 6th edn, pp. 489-501G. Edited by L. Mandell, J. E. Bennett \& R. Dolin. Philadelphia: Elsevier.

WHO (2000). Anti-tuberculosis Drug Resistance in the World. Report no. 2: Prevalence and Trends. Publication no. WHO/CDS/TB/ 2000.278. Geneva: World Health Organization.

WHO (2002). Global Tuberculosis Control: Surveillance, Planning, Financing. WHO report 2002. Publication no. WHO/CDS/TB/ 2002.295. Geneva: World Health Organization.

WHO (2004). Anti-tuberculosis Drug Resistance in the World: Third Global Report. Publication no. WHO/HTM/TB/2004.343. Geneva: World Health Organization.

Zhang, M., Yue, J., Yang, Y., Zhang, H., Lei, J., Jin, R., Zhang, X. \& Wang, H. (2005). Detection of mutations associated with isoniazid resistance in Mycobacterium tuberculosis isolates from China. J Clin Microbiol 43, 5477-5482. 